readily and it has been confirmed that where abnormalities existed opticians did not fail to detect them. ${ }^{1}$ It is, however, an assumption to conclude that an optician is therefore better able to examine a retina. It is true that they are trained in fundoscopy, but any abnormality that might be found beyond their experience of the normal must be referred to the general practitioner, who in turn is likely to refer the patient to the hospital eye service. It is our experience that most of these referrals are for lesions which are of no clinical importance and it is exceptionally rare for diabetes to be detected by the observation of retinopathy in a person who is otherwise not known to be suffering from the disease.

It is perhaps regrettable that many diabetic patients receive their only eye examination by the optician, even though most will also be under the care of the general practitioner or a physician. General practitioners do express anxiety about their ability to detect retinopathy; however, it is not difficult for a doctor to acquire the necessary techniques and apply them routinely. As general practitioners become increasingly aware of the need to detect diabetic retinopathy many are improving their own fundoscopy techniques, and many large practices are ensuring that at least one partner obtains and continues to enjoy sufficient experience in the examination of the retina so that fundoscopy is no more of a worry than measuring blood pressure or listening to changes in heart sounds. It would also be helpful if physicians caring for diabetics routinely dilate their pupils and examine their fundi. Very many do not.

Ophthalmic opticians provide a valuable service in testing for glasses, and they may play a part in routine testing of intraocular pressure. However, mixing the commercial aspect of selling glasses with the primary care of patients has led many ophthalmologists to express concern that the screening of diabetics may expand into the market place.

Dr Yudkin presents a compelling case for the screening of diabetic retinas, but let this be done by doctors and not by ophthalmic opticians. The discussion which has been engendered by the proposal to charge people for an eye test by opticians should serve to highlight the problem of screening of diabetics and to encourage doctors to take upon themselves this responsibility.

JOHN D SCOTT

Director,

Regional Retina Service

East Anglia

Declan Flanagan

Addenbrooke's Hospital,

Cambridge CB2 2QQ

1 Burns-Cox CJ, Dean Hart JC. Screening of diabetics for retinopathy by ophthalmic opticians. Br Med f 1985;290: $1052-4$.

\section{Treatment of Paget's disease of bone}

SIR,-Like Dr H I J Harinck and others (21 November, p 1301), ${ }^{1}$ we have found aminohydroxypropylidene bisphosphonate to be highly effective and safe in the treatment of Paget's disease of bone. ${ }^{2}$ We believe, however, that the regimen of intravenous aminohydroxypropylidene bisphosphonate which they gave to 32 patients, consisting of 10 consecutive daily infusions of $20 \mathrm{mg}$ aminohydroxypropylidene bisphosphonate intravenously with the response monitored closely by 24 hour urine hydroxyproline estimation, is expensive and impracticable for routine use. Most affected patients are elderly, and daily treatment-certainly with 24 hour urine collections-requires the expense and disruption of inpatient admission.

We have developed an equally successful treatment strategy which depends on a course of weekly or fortnightly infusions of aminohydroxypropylidene bisphosphonate intravenously in $0.9 \%$ saline, and we have now treated 133 patients in this way. Our current regimen is to start with a single infusion of $30 \mathrm{mg}$ in $250 \mathrm{ml}$ saline over two hours, followed in one week by $60 \mathrm{mg}$ in $500 \mathrm{ml}$ saline over four hours; the latter is repeated at 14 day intervals, twice for disease of moderate extent and activity (total dose of $210 \mathrm{mg}$ ) and five times for more extensive disease (total dose of $390 \mathrm{mg}$ ). If it is considered necessary then estimation of a fasting morning hydroxyproline:creatinine ratio is perfectly adequate, but for week to week monitoring of response alkaline phosphatase estimations are generally sufficient. We do not agree that "short intravenous courses must be followed by oral aminohydroxypropylidene bisphosphonate" in patients with high disease activity. Such patients simply require longer and higher doses intravenously, and for resistant cases of "megaPaget's" we have eventually given as much as $120 \mathrm{mg}$ intravenously weekly as an infusion over four hours for 12 weeks without adverse effects, and usually with good response.

Dr Harinck and his colleagues also state that about $1 \%$ of oral aminohydroxypropylidene bisphosphonate is absorbed, but this calculation is based on the most tenuous of indirect evidence. Until much more is known of the absorption and pharmacodynamics of aminohydroxypropylidene bisphosphonate it seems unlikely that a satisfactory pharmaceutical preparation of oral aminohydroxypropylidene bisphosphonate will become available, especially for treatment of a non-malignant disease that in most cases can be so effectively controlled by outpatient administration of a short course of intravenous infusions.

Finally, concerning the mechanism of action of aminohydroxypropylidene bisphosphonate in this condition, we would urge caution in extrapolating from the authors' excellent animal experiments on normal rat and mouse osteoclasts and precursors to the highly abnormal osteoclasts of Paget's disease a condition which as far as we know is confined to humans.

DAVID C ANDERSON JUDY C CANTRILI

Department of Medicine (Endocrinology),

Hope Hospital, Salford M6 8HD

1 Harinck HIJ, Bijvoet OLM, Blanksma HJ, DallinghausNienhuys PJ. Efficacious management with amino-bisphosphonate (APD) in Paget's disease of bone Clinical Orthopaedics and Related Research 1987;217:79-98.

2 Cantrill JA, Buckler HM, Anderson DC. Low dose intravenou 3-amino-1-hydroxypropylidene-1,1-bisphosphonate (APD) for the treatment of Paget's disease of bone. Ann Rheum Dis 1986;45:1012-8.

\section{Caffeine and health}

SIR,-Dr C H Ashton discussed possible relations between caffeine and health, particularly menta health (21 November, p 1293). We have investigated associations between coffee consumption and mental problems in a general population with high coffee consumption.

During the second Troms $\varnothing$ heart study $(1979-80)$ nearly 143000 men and women answered several questions about, among other topics, coffee consumption and symptoms of mental problems (depression, difficulty in coping with the problems of daily life, insomnia). The response rate to the self administered questionnaire was $88 \% .^{1} \mathrm{We}$ compared the prevalence of these reported mental problems in subjects with a high coffee consumption ( $>8$ cups per day) with the prevalence in subjects with lower consumption. The table gives the age adjusted figures.

We found no association between high coffee consumption and mental problems in men, whereas in women consistent and statistically significan $(p \leqslant 0.001$ for depression and problems with coping) associations were observed (table). The reason for the lack of effect in men may be that the highest consumption category considered in this study ( $>8$ cups of coffee per day) does not represent a sufficiently heavy consumption in men; $16 \%$ of the men in this population drank $>8$ cups of coffee daily whereas the corresponding figure among women was $9 \cdot 6 \%$.

Coffee consumption and mental problems. Prevalence (\%) of self reported mental problems according to coffee consumption (Tromsø 1979-80)

\begin{tabular}{|c|c|c|c|c|c|c|}
\hline \multirow{3}{*}{$\begin{array}{l}\text { Coffee } \\
\text { consumption } \\
\text { (cups/day) }\end{array}$} & \multicolumn{6}{|c|}{$\%$ Reporting symptoms of mental problems } \\
\hline & \multicolumn{2}{|c|}{ Depression } & \multicolumn{2}{|c|}{$\begin{array}{l}\text { Problems with } \\
\text { coping }\end{array}$} & \multicolumn{2}{|c|}{ Insomnia } \\
\hline & Men & Women & Men & Women & Men & Women \\
\hline $\begin{array}{l}>8 \\
\leqslant 8\end{array}$ & $\begin{array}{l}9 \\
9\end{array}$ & $\begin{array}{l}16 \\
12\end{array}$ & $\begin{array}{l}7 \\
6\end{array}$ & 11 & $\begin{array}{l}5 \\
5\end{array}$ & $\begin{array}{r}10 \\
8\end{array}$ \\
\hline
\end{tabular}

As in all cross sectional studies, we cannot conclude whether coffee consumption is the cause or the effect of the self reported mental problems. When the associations found in women are adjusted for cigarette smoking they tend to disappear. Thus, in this population with relatively high consumption, coffee consumption is probably part of a lifestyle associated with mental problems.

Unfortunately, we do not have information about other symptoms of mental discomfort. Thus, we cannot exclude relations between coffee drinking and, for example, anxiety. Furthermore it cannot be ruled out that subjects who experience effects of coffee drinking on psychological health reduce their coffee consumption, thereby making it less likely that a relation will be observed. Finally, we cannot exclude the possibility that coffee consumption influences the symptoms of mental ill health in subjects with very heavy coffee consumption. Such effects may, however, be difficult to show in a cross sectional study in a general population because of problems with confounding and because few individuals, even in Norway, where coffee consumption is high, have a very heavy chronic use.

BJARNE K JACOBSEN VIDJE HANSEN

Institute of Community Medicine,

University of Tromsø,

Tromsø, Norway

1 Thelle DS, Arnesen E, Førde OH. The Tromsø heart study. Does coffee raise serum cholesterol? N Engl f Med 1983;308: 1454-7.

\section{Clinical experimentation in obstetrics}

SIR,-Do those who, like Professor R J Lilford, worship the icon of the double blind random placebo matched control trial (21 November, p 1298) ever stop to think about not only the pedestrian rate but also the mediocre quality of the research into which they have poured resources? None of the major advances in obstetric knowledge or practice have come from double blind controlled trials. If a question is of real importance, or the answer has major impact, such a trial is not needed for its solution and controls are merely to assess "background noise." 